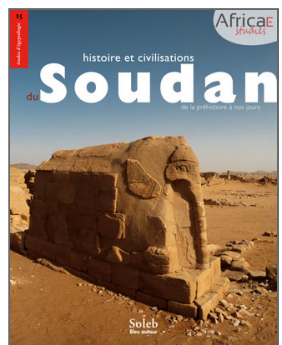

Olivier Cabon (dir.)

Histoire et civilisation du Soudan

De la préhistoire à nos jours

\title{
La population
}

\section{Odile Nicoloso et Olivier Cabon}

DOI : 10.4000/books.africae.2962

Éditeur : Africae, Soleb, Bleu autour

Lieu d'édition : Paris, Khartoum

Année d'édition : 2017

Date de mise en ligne : 17 janvier 2022

Collection : Africae Studies

EAN électronique : 9782493207074

\section{OpenEdition}

\section{Books}

http://books.openedition.org

\section{Référence électronique}

NICOLOSO, Odile ; CABON, Olivier. La population In : Histoire et civilisation du Soudan : De la préhistoire à nos jours [en ligne]. Paris, Khartoum : Africae, 2017 (généré le 28 janvier 2022). Disponible sur Internet <http://books.openedition.org/africae/2962>. ISBN : 9782493207074. DOI : https://doi.org/10.4000/ books.africae. 2962. 


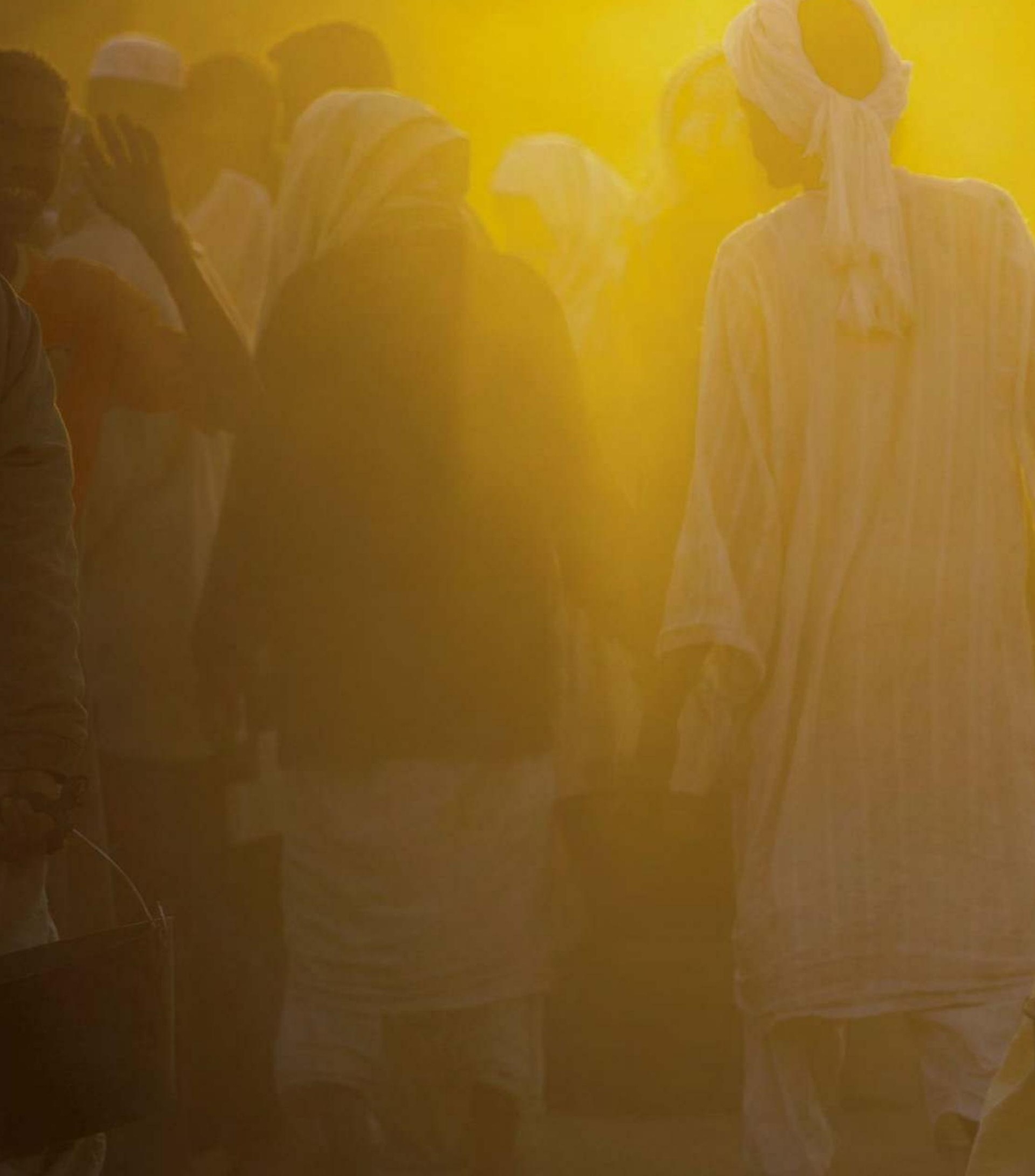


la population

Odile Nicoloso et Olivier Cabon 
al-Kufrah $\quad$ principales populations du Soudan 
* Données

Banque mondiale.

D'après la carte

d'Hèlène David-Cuny (se reporter p. 25). Pour les 18 États composant le Soudan, voir p. 761
Le Soudan, bilad as-sudan, le pays des noirs, est une société tribale, multiculturelle, multiethnique, multilinguiste. (On compte environ 570 tribus réparties en 56 groupes ethniques.) La langue arabe y est dominante (ainsi que la religion musulmane), mais on recense environ... 125 langues. L'anglais de l'ancien colonisateur reste une langue de référence.

En 2015, la population* a été estimée à environ 40 millions de personnes - elle était d'environ 7,5 millions en 1960 (en incluant les États qui forment désormais le Soudan du Sud) et a cru à peu près régulièrement (le taux de croissance actuel est de 1,78\%). Le taux de natalité est de 30,01 naissances pour 1000 habitants et le taux de mortalitéde 7,87 décès pour 1000 habitants. L'âge médian est de 19,1 ans: 40,8\% de la population a moins de 15 ans; $20,2 \%$ entre 15 et 24 ans; $31,8 \%$ entre 25 et 54 ans; $3,9 \%$ entre 55 et 64 ans; 3,3\% 65 ans et plus. L'espérance de vie à la naissance est de 63,32 ans. La population urbaine représente 33,2\% du total: en 2012 le "Grand Khartoum" regroupait environ 7 millions d'habitants.

Les deux principales tribus arabes sont les Jaalayin et les Juhayna (Kababish, Baggara, Shukria, Rufaa) qui peuvent respectivement être considérés comme sédentaires et nomades. Les Bagarra qui vivent au Kordofan du Sud et au Darfour — et sont sous-divisés en Misserya et Rizeigat — sont des tribus d'éleveurs de bovins (bagar en arabe) qui nomadisent entre le Tchad et le Nil, tandis que les nomades éleveurs de dromadaires sont dénommés Abbala. Les Bedja et les Rashaïda vivent à l'est le long de la côte de la mer Rouge. Les Bedja sont un des plus anciens groupes soudanais, c'est un peuple nomade fier de ses troupeaux de chameaux. Les Four forment la principale population sédentaire de la province du Darfour. Les Nouba peuplent les Monts Nouba dans le Kordofan: enclavée au milieu des «montagnes", chaque vallée pratique une langue différente - ce qui fait de cette région un véritable laboratoire pour les linguistes.

«Fallata» est l'appellation des descendants de nombreux pèlerins de retour de La Mecque. À partir de la fin du XIX ${ }^{e}$ siècle, ils sont venus d'Afrique de l'Ouest ou du Maghreb pour embarquer à Port-Soudan, en direction de l'Arabie Saoudite. Sur le chemin du retour, ils décidaient parfois de rester, se mariaient et devenaient Soudanais. Les Nubiens qui vivent dans la région de Dongola et Wadi Halfa ne sont ni arabes ni noirs. Ils ont leur propre langue, une identité culturelle très forte, une histoire ancienne qui commence avant le royaume de Koush. C'est un peuple fier, marqué par l'exil suite à la construction du barrage d'Assouan qui a obligé des milliers d'entre eux à quitter leurs villages, parfois millénaires, engloutis sous les eaux.

La diversité ethnique est une des principales caractéristiques du Soudan. Les rapports entre les ethnies sont souvent le résultat de la mobilité de la population et vont de la coopération mutuelle à l'hostilité déclarée 